\title{
Using Vegetative Indices to Quantify Agricultural Crop Characteristics
}

\author{
Svitlana Kokhan ${ }^{1 *}$, Anatoliy Vostokov' \\ ${ }^{1}$ Department of Geoinformatics and Aerospace Research of the Earth, National University of Life and \\ Environmental Sciences of Ukraine, 17 Vasylkivska St., 03040 Kyiv, Ukraine \\ *Corresponding author's e-mail: kokhan_s@nubip.edu.ua
}

\begin{abstract}
In this study, the winter wheat aboveground biomass (AGB), leaf area index (LAI) and leaf nitrogen concentration (LNC) were estimated using the vegetation indices, derived from a high spatial resolution Pleiades imagery. The AGB, LAI and LNC estimation equations were established between the selected VIs, such as NDVI, EVI and SAVI. Regression models (linear and exponential) were examined to determine the best empirical regression equations for estimating the crop characteristics. The results showed that all three vegetation indices provide the AGB, LAI and LNC estimations. The application of NDVI showed the smallest value of RMSE for the aboveground biomass estimation at stem elongation and heading of winter wheat. EVI gave the best significant estimation of LNC and showed better results to quantify winter wheat vegetation characteristics at stem elongation phase. This study demonstrated that Pleiades high spatial resolution imagery provides in-situ crop monitoring.
\end{abstract}

Keywords: vegetation indices, aboveground biomass, leaf area index, leaf nitrogen concentration

\section{INTRODUCTION}

Farming is one of the most important branches of the Ukraine's economy. In addition, over 30 per cent of the country's exports belong to the agricultural sector. Most Ukrainian soils are suitable for growing winter cereals. Winter wheat is one of the key crops that is grown throughout the country.

The crop growth and development can be monitored with remote sensing data of various spatial, temporal and spectral resolutions, acquired at different platforms. A large number of studies are devoted to the crop growth indicators, such as leaf area index, leaf nitrogen concentration and their relationship with the crop spectral properties. Various approaches and techniques for providing an efficient crop monitoring are presented in papers. The availability of free remote sensing data as well as commercial satellite data acquisition, and the use of ground-based sensors, provides the time series data for crop growth monitoring.
The aboveground biomass is an important index for the crop growth and can be the basic factor in detecting and estimating the yield of crop. The traditional methods in the crop biomass estimation need a large resource. They cannot effectively provide the crop state observation in a large area. In many studies, the satellite-based vegetation indices (VIs) are the most commonly used models for the estimation of the biomass [Schlerf et al. 2005, Zheng et al. 2004], LAI [Turner et al. 1999] and plant $\mathrm{N}$ content [Xue and $\mathrm{Su} 2017]$. VI is the mathematical transformation of the original spectral reflectance, which are used for interpreting vegetation biomass and canopy [Kokhan 2011, He et al. 2006, Rahman et al. 2003]. The vegetation indices are widely used to remove the variations caused in spectral reflectance while measuring biophysical properties caused due to the soil background, sun view angles, and atmospheric conditions [Niu et al. 2000]. The assessment of the vegetation properties, based on the use of VIs and their derivatives, mainly includes the following categories: structural (biomass) [Myneni et al. 
1995], LAI [Turner et al. 1999], FVC [Gitelson et al. 2002] and FAPAR [Vin a1 and Gitelson 2005]; biochemical (chlorophyll and other pigments, water content, nitrogen, lignin etc.) [Xue and $\mathrm{Su}$ 2017] and plant physiological / plant stress characteristics [Berger et al. 2014]. VIs based on remote sensing data have been widely used in the research implemented for quantitative and qualitative evaluations of vegetation cover and crop monitoring. Some researchers adopted red edge parameters of rice and maize canopy spectral to estimate the weight of the aboveground biomass, and the correlation between them was significant [Filella and Penuelas 1994].

Currently, various VIs based on remote sensing (RS) data are used to effectively monitor the crop state. They provide regular feedback on the status and productivity of agricultural fields. The main problem of most studies is the need to use a comparative assessment of the values of different VIs derived from optical satellite systems that must undergo mandatory atmospheric correction. The information on the crop growth and dynamics, obtained by the RS data, provides useful, objective information for managing the agricultural production and crop yield estimates [Huete et al. 2002].

When the remote sensing of vegetation uses passive sensors, the information contains the data about various parameters of vegetation [Chang et al. 2016], which are determined by the chemical and morphological characteristics, as well as by the surface of the leaves [Zhang and Kovacs 2012].

A number of studies showed that spectral indices have a high correlation with the state of $\mathrm{N}$ in crops [Fitzgerald et al. 2010, Tian et al. 2011]. The correlations of LAI and biomass with spectral data, using linear regression methods are shown in papers [Glenn et al. 2008, Verrelst et al. 2012]. The leaf area index (LAI) is a major canopy biophysical parameter. It can be used in the study of the physiological processes in vegetation [Mulla 2013]. The RS data provides a quick approach to the evaluation of crop LAI and to the development of various methodologies for LAI estimation at diverse scales and for different types of vegetation canopies [Hansen and Schjoerring 2003]. There are two common types of remote sensing methods that can be used for the LAI estimation. The first is the statistical method based on a regression analysis. Expression is obtained from the relationship between the spectral reflectance at the crop canopy level and the ground-measured LAI [Baret et al. 2007]. The other type is inverted radiative transfer model. It includes the spectral reflectance at the crop canopy level [Boissard et al. 1992].

Niu et al. showed, that fresh LNC can be estimated using the reflection spectrum of the first derivative at $2120 \mathrm{~nm}$ and $1120 \mathrm{~nm}$ [Niu et al. 2000]. Cho and Skidmore reported the allocation of two optimal regions of the red edge with high sensitivity to N [Cho and Skidmore 2006]. Two vegetation indices, Normalized Difference Nitrogen Index (NDNI) and Normalized Difference Lignin Index (NDLI) were used to assess N and lignin in native shrubs[Serrano et al. 2002]. $\mathrm{Li}$ et al. showed, that partial least square regression (PLSR) could accurately predict LNC in winter wheat and winter oilseed rape [Ecarnot et al. 2013].

The quality of wheat is based primarily on the content of protein, the main component of which is nitrogen. Nitrogen must be in sufficient quantities to obtain a high level of protein [Wuest and Cassman 1992]. The presence of nitrogen in plants can be estimated using the spectral reflectivity of crops [Hinzman et al. 1986, Bsaibes et al. 2009]. Evaluation of various spectral indicators of vegetation is an important factor in determining the requirements for the use of $\mathrm{N}$ in the middle of the season.

Most of the previous studies related to the $\mathrm{N}$ and biomass estimation used low and moderateresolution remote sensing data [Goetz 1997]. In this research, the authors have applied the Pleiades data with a high spatial resolution to quantify the winter wheat characteristics.

\section{THE SUBJECT OF RESEARTH AND METHODS}

Per-field measurements were conducted in field locations within the production areas in western part of Forest-Steppe on typical chernozem soil and chernozem podzolic soil. The experimental variables included high agricultural fertilizer background and different varieties of winter wheat. The data, obtained within the experimental fields in northern Forest-Steppe, are not included in this paper.

The plant sampling locations were established at the centroids of clusters, which differed in the crop state based on Landsat satellite imagery. 
ArcGIS 10.4 software was used for sampling points and geodata processing. The coordinates of centroids were loaded into a Trimble GPS and used for plant sampling. The field samples of the aboveground biomass were gathered using two $1.13 \mathrm{~m}$ rows in three places along the diagonal of the plot. The plants were cut at ground height. The plant samples were dried at $105^{\circ} \mathrm{C}$ and weighed. The leaf $\mathrm{N}$ concentration was determined according to the Kjeldahl method. The ground data collection was done quasi synchronically with satellite image acquisition.

The Pleiades-1A (1B) satellite image data with a spatial resolution of $0.5 \mathrm{~m}$ obtained in the visible and near infrared ranges were applied in the research [ASTRIUM GEO-Information 2012]. The Pleiades-1A/1B multispectral data were acquired at stem elongation of winter wheat and at heading phase. The satellite images were atmospherically corrected. TerrSet(IDRISI) was used for the satellite image processing.

The vegetation indices derived from the Pleiades high-resolution imagery were used to develop regression models in order to assess the leaf nitrogen concentration (LNC), the above ground biomass (AGB) and canopy biophysical parameter leaf area index (LAI). The goal of a research was to estimate the relationships between the vegetation indices and the crop canopy characteristics. The Normalized Difference Vegetation Index (NDVI), Enhanced Vegetation Index (EVI), which is sensitive to the vegetation growth levels, and SAVI (Soil-Adjusted Vegetation Index) were used in the study. The following tasks were to be resolved in the research: pre-processing of time series remote sensing data; monitoring the winter wheat state through the period of stem elongation to heading based on different VIs and crop productivity indicators; evaluation of various vegetation indices for quantifying the winter wheat productivity indicators. The vegetation indices used in the study are shown in Table 1.

\section{RESULTS AND DISCUSSION}

The remote sensing vegetation indices, that measure the plant spectral characteristics based on reflectance in the visible wavelengths and near-infrared diapason are often used to estimate the aboveground biomass, the plant nitrogen content and crop biophysical parameters. The vegetation indices obtained from red and near infrared bands have the small sensitivity to the vegetation growth conditions. A group of VIs developed to minimize the effect of the soil background on retrieving the vegetation information is represented

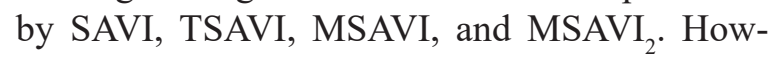
ever, they also reduce their sensitivity within the period of crop growth. The Enhanced Vegetation Index (EVI) is more sensitive to the topographic conditions than is the NDVI, and it has improved sensitivity to the high biomass areas. The vegetation indices used in the present research, such as NDVI, EVI and SAVI were derived from the Pleiades satellite imagery at two periods - stem elongation of winter wheat within the second decade of May and at the heading phase at the beginning of June.

The regression analysis was conducted to correlate the NDVI, EVI and SAVI values with the aboveground biomass. The regression analysis between VIs using the linear equation both for NDVI $\left(\mathrm{R}^{2}=0.90\right)$ and SAVI $\left(\mathrm{R}^{2}=0.89\right)$, and exponential model for EVI with the coefficient of determination $\mathrm{R}^{2}=0.93$ showed significant correlations at $\mathrm{p}<0.050$ at stem elongation. The higher value of the $\mathrm{R}^{2}$ was obtained at stem elongation compared to the winter wheat heading (Tables 2-3).

The exponential models provided higher correlations between all VIs and the aboveground biomass at heading. The relationships between VIs and aboveground biomass are shown in Figures 1 and 4. The estimated winter wheat biomass was validated with the ground-based

Table 1. Definition of spectral indices. Bands are designated in the formulas as R (red), B (blue), G (green), NIR (near-infrared), and L (soil line)

\begin{tabular}{|c|l|l|l|}
\hline Index & \multicolumn{1}{|c|}{ Name } & \multicolumn{1}{c|}{ Citation } & \multicolumn{1}{c|}{ Formula } \\
\hline NDVI & Normalized Difference Vegetation Index & Tucker $(1979)$ & $(\mathrm{NIR}-\mathrm{R}) /(\mathrm{NIR}+\mathrm{R})$ \\
\hline $\mathrm{EVI}$ & Enhanced Vegetation index & Huete et al. $(2002)$ & $2.5(\mathrm{NIR}-\mathrm{R}) /(\mathrm{NIR}+6 \times \mathrm{R}-7.5 \times \mathrm{B}+1)$ \\
\hline SAVI & Soil-Adjusted Vegetation Index $(\mathrm{L}=0.5)$ & Huete $(1988)$ & {$[(\mathrm{NIR}-\mathrm{R}) /(\mathrm{NIR}+\mathrm{R}+\mathrm{L})](1+\mathrm{L})$} \\
\hline
\end{tabular}


Table 2. Correlations between VIs and agricultural crop characteristics. Correlations are significant at $\mathrm{p}<0.050$ (stem elongation of winter wheat)

\begin{tabular}{|c|c|c|c|c|c|}
\hline VI/Parameter & Mean & Std.Dv. & $r(X, Y)$ & $\mathrm{R}^{2}$ & Equation \\
\hline NDVI & 0.720 & 0.043 & & & $y=27.872 x-14.535$ \\
\hline AGB & 5.504 & 1.337 & 0.95 & 0.90 & \\
\hline NDVI & 0.720 & 0.043 & & & $y=0.1001 e^{4.7853 x}$ \\
\hline LAI & 3.218 & 0.692 & 0.90 & 0.82 & \\
\hline NDVI & 0.720 & 0.043 & & & $y=8.4155 x-1.8612$ \\
\hline LNC & 4.195 & 0.388 & 0.97 & 0.94 & \\
\hline EVI & 0.518 & 0.084 & & & $y=1.067 e^{3.1047 x}$ \\
\hline AGB & 5.504 & 1.337 & 0.96 & 0.93 & \\
\hline EVI & 0.518 & 0.084 & & & $y=0.8206 e^{2.5908 x}$ \\
\hline LAI & 3.218 & 0.692 & 0.93 & 0.87 & \\
\hline EVI & 0.518 & 0.084 & & & $y=4.4519 x+1.8922$ \\
\hline LNC & 4.195 & 0.388 & 0.97 & 0.95 & \\
\hline SAVI & 0.468 & 0.064 & & & $y=19.756 x-3.7415$ \\
\hline AGB & 5.504 & 1.337 & 0.94 & 0.89 & \\
\hline SAVI & 0.468 & 0.064 & & & $y=0.6891 e^{3.2406 x}$ \\
\hline LAI & 3.218 & 0.692 & 0.89 & 0.79 & \\
\hline SAVI & 0.468 & 0.064 & & & $y=5.7323 x+1.5155$ \\
\hline LNC & 4.195 & 0.388 & 0.96 & 0.91 & \\
\hline
\end{tabular}

Table 3. Correlations between VIs and agricultural crop characteristics. Correlations are significant at $\mathrm{p}<0.050$ (heading of winter wheat)

\begin{tabular}{|c|c|c|c|c|c|}
\hline VI/Parameter & Mean & Std.Dv. & $r(X, Y)$ & $\mathrm{R}^{2}$ & Equation \\
\hline NDVI & 0.645 & 0.049 & & & $y=0.1565 e^{5.7746 x}$ \\
\hline AGB & 6.796 & 2.044 & 0.90 & 0.81 & \\
\hline NDVI & 0.645 & 0.049 & & & $y=0.3646 e^{3.0278 x}$ \\
\hline LAI & 2.602 & 0.402 & 0.92 & 0.84 & \\
\hline NDVI & 0.645 & 0.049 & & & $y=4.2905 x+1.3101$ \\
\hline LNC & 4.078 & 0.231 & 0.91 & 0.83 & \\
\hline EVI & 0.507 & 0.083 & & & $y=1.0771 e^{3.5395 x}$ \\
\hline AGB & 6.796 & 2.044 & 0.93 & 0.86 & \\
\hline EVI & 0.507 & 0.083 & & & $y=1.0217 e^{1.8182 x}$ \\
\hline LAI & 2.602 & 0.402 & 0.93 & 0.87 & \\
\hline EVI & 0.507 & 0.083 & & & $y=2.5654 x+2.776$ \\
\hline LNC & 4.078 & 0.231 & 0.92 & 0.84 & \\
\hline SAVI & 0.502 & 0.069 & & & $y=0.8422 e^{4.0655 x}$ \\
\hline AGB & 6.796 & 2.044 & 0.90 & 0.81 & \\
\hline SAVI & 0.502 & 0.069 & & & $y=0.929 e^{2.0262 x}$ \\
\hline LAI & 2.602 & 0.402 & 0.87 & 0.76 & \\
\hline SAVI & 0.502 & 0.069 & & & $y=2.9957 x+2.573$ \\
\hline LNC & 4.078 & 0.231 & 0.91 & 0.81 & \\
\hline
\end{tabular}

measurements. The results suggested that the root mean square error (RMSE) of aboveground biomass estimated for the three VIs was not significant at stem elongation and had smaller values compared to the results at heading (Figure 7).

The results shown in Figure 3 and Figure 6 indicate that NDVI, EVI and SAVI have strong relationships between VIs and LAI. In the exponential model, EVI provided the most significant relations with the $\mathrm{R}^{2}$ value of 0.87 for both stages of crop development. As the EVI has sensitivity to the high biomass areas and to the changes in the solar elevation and azimuth angles, its RMSE value has become similar to the NDVI RMSE at winter wheat heading (Figure 8).

The highest coefficients of determination of the linear regression between the LNC and VIs were obtained both for the NDVI and EVI 

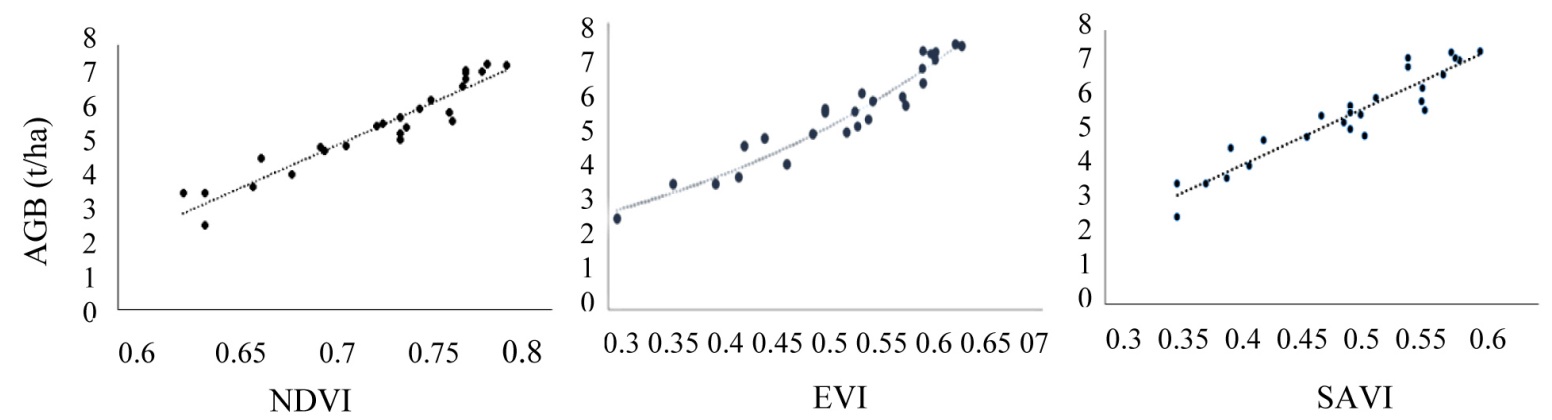

Figure 1. The relation between VIs and AGB (Stem elongation)
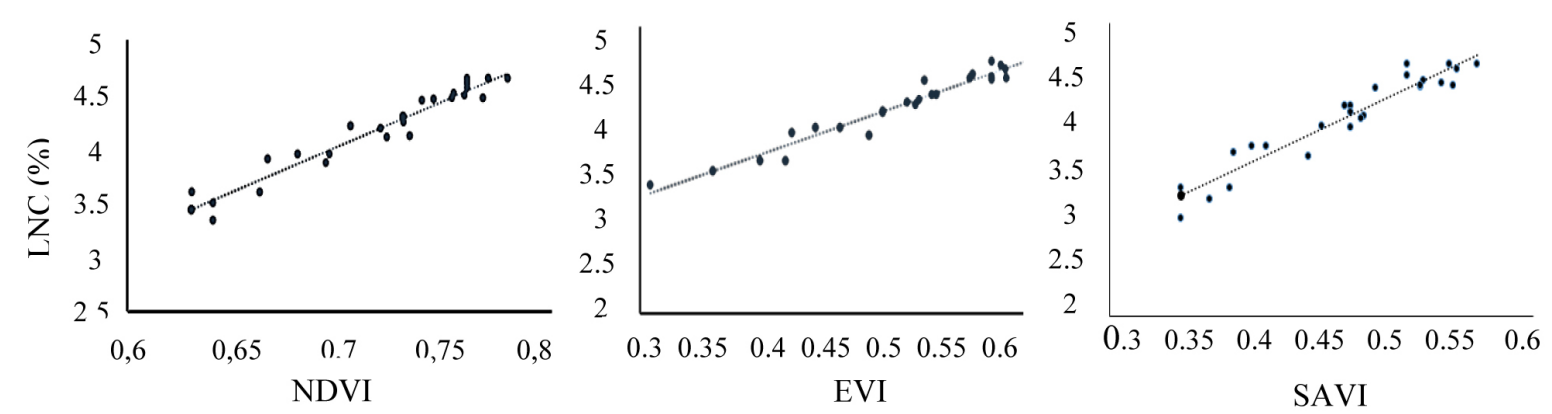

Figure 2. The relation between VIs and LNC (Stem elongation)
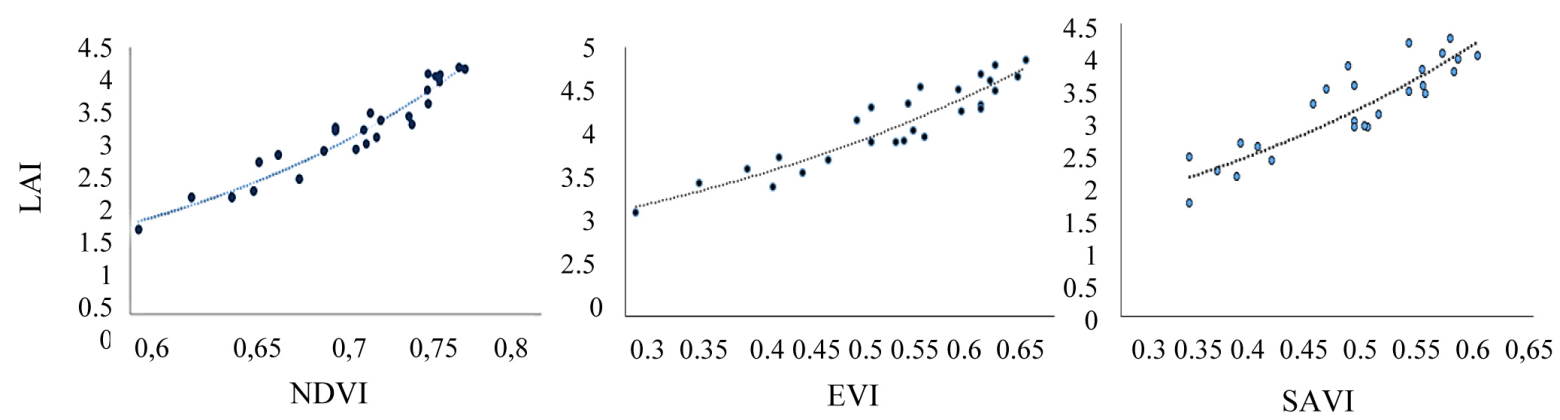

Figure 3. The relation between VIs and LAI, $\mathrm{m}^{2} / \mathrm{m}^{2}$ (Stem elongation)
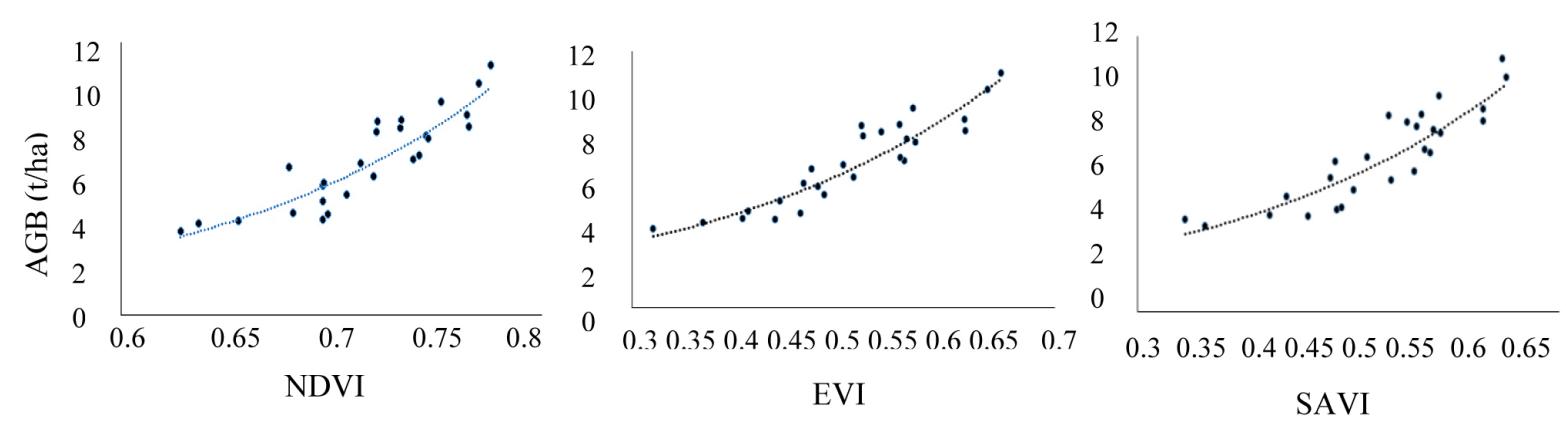

Figure 4. The relation between VIs and AGB (Heading) 


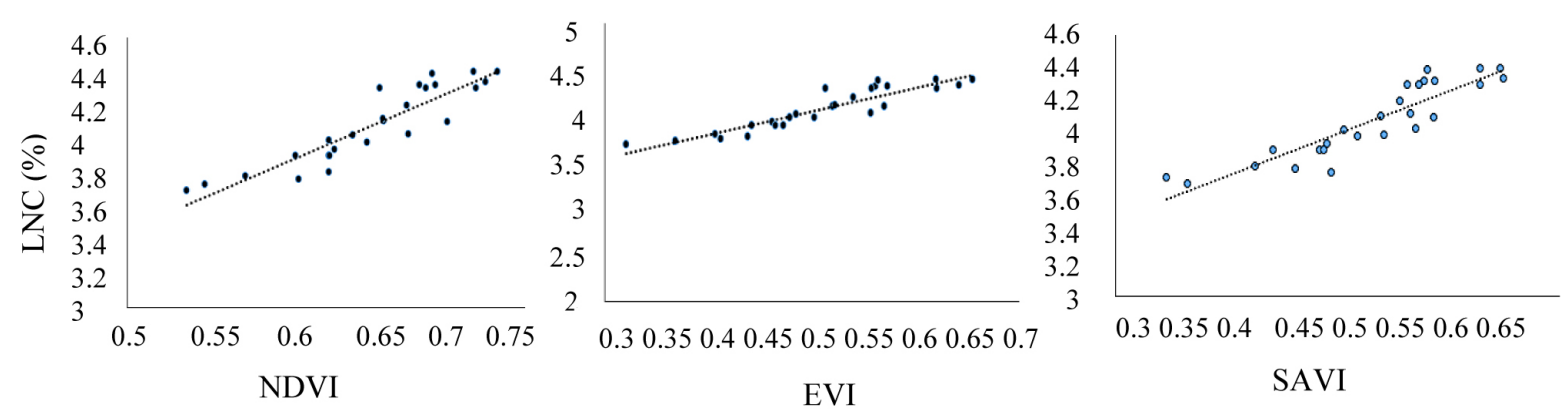

Figure 5. The relation between VIs and LNC (Heading)
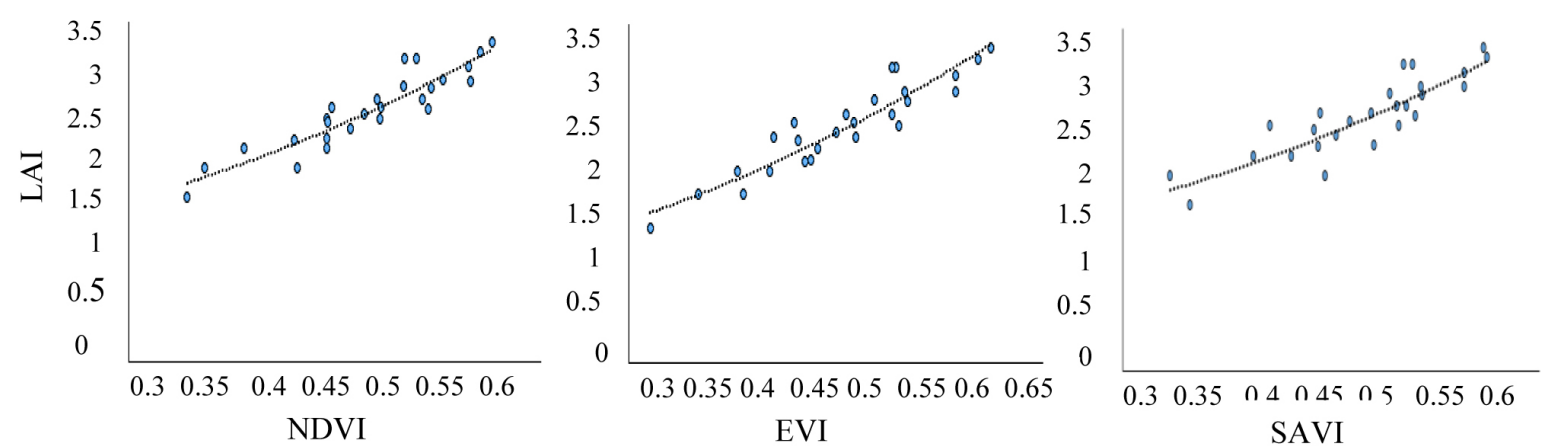

Figure 6. The relation between VIs and LAI, $\mathrm{m}^{2} / \mathrm{m}^{2}$ (Heading)

Heading

Stem elongation

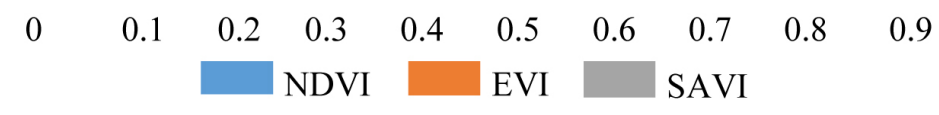

Fig. 7. Root mean square errors of estimated aboveground biomass

Heading

Stem elongation

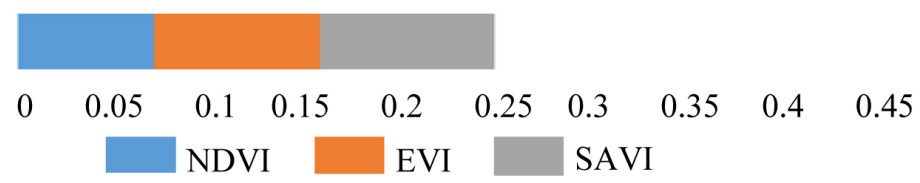

Fig. 8. Root mean square errors of estimated LAI

Heading

Stem elongation

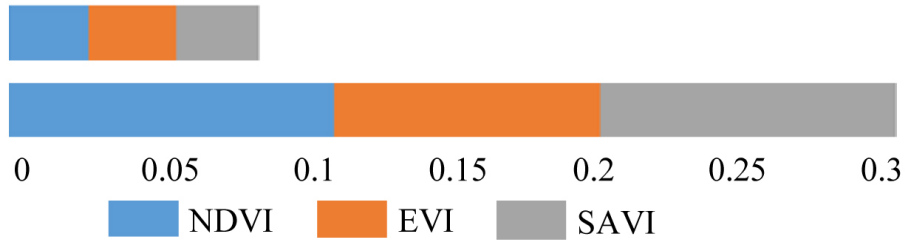

Fig. 9. Root mean square errors of estimated LNC 
$\left(\mathrm{R}^{2}=0.94\right.$ and 0.95 at stem elongation, 0.83 and 0.84 at heading phase respectively), (Figures 2, 5). The results suggest that RMSE for the three VI was $0.12 \%$ for NDVI, $0.09 \%$ for EVI and $0.10 \%$ for SAVI at stem elongation, and $0.03 \%$ for all VIs at heading (Figure 9).

On the basis of the given results it can be conclude, that all three vegetation indices provide the AGB, LAI and LNC estimations. Each spectral VI has its own limitations and positive features. Traditional application of NDVI during the period of intensive biomass development provided the smallest value of RMSE for the aboveground biomass estimation at both stages. Meanwhile, it gave higher errors for the estimation of LNC.

EVI provided significantly better estimation of the leaf nitrogen content. In general, this VI showed better results to quantify the winter wheat vegetation characteristics at the stem elongation phase. For an efficient application of the vegetation indices in agriculture, many factors should be taken into consideration, such as sensitivity to biophysical parameters, topographic effects, noise caused by canopy background, atmospheric effects, solar elevation and azimuth angles, fraction of vegetation cover, vegetation density, features of cultivated crop and stage of crop development.

\section{CONCLUSIONS}

In this study, the authors estimated the winter wheat aboveground biomass (AGB), leaf area index (LAI) and leaf nitrogen concentration (LNC) using the vegetation indices, derived from a high spatial resolution remote sensing imagery Pleiades. The AGB, LAI and LNC estimation equations were established between the selected VIs, such as NDVI, EVI and SAVI. Regression models (linear and exponential) were examined to determine the best empirical regression equations for estimating agricultural crop characteristics.

The results showed that all three vegetation indices provide the AGB, LAI and LNC estimations. The application of NDVI during the period of intensive biomass development provided the smallest value of RMSE for the aboveground biomass estimation at the phase of winter wheat stem elongation and heading. EVI provided the best significant estimation of LNC and showed better results to quantify the winter wheat vegetation characteristics at the stem elongation phase.
This study demonstrated that high spatial resolution satellite data provides the in-situ monitoring. In addition, the remote sensing technology can capture the variability of the crop vegetation characteristics under different conditions. The Pleiades data could be used in test polygons and within the small farm areas. The potential use of high spatial resolution satellites could be useful for precision farming.

Many factors should be taken into consideration for the efficient application of the vegetation indices in agriculture.

\section{Acknowledgments}

Publication is funded by the Polish National Agency for Academic Exchange under the International Academic Partnerships Programme from the project "Organization of the 9th International Scientific and Technical Conference entitled Environmental Engineering, Photogrammetry, Geoinformatics - Modern Technologies and Development Perspectives".

The authors thank to Mr. Maksim Maiarchuk for providing sampling and measurements. We would like to express appreciation to Mr. Eric Duclos-Gendreu («Airbus Defence \& Space») and Mr. Oles Yasinsky (“TVIS-Info Ltd") for helping in operative acquisition of satellite images.

\section{REFERENCES}

1. Baret, F., Hagollec, O., Geiger, B., Bickering, P., Miras, B., Huc, M., Berthelot, B., Niño, F., Weiss, M., Samain, O., Roujean, J.L., Leroy, M. 2007. LAI, fAPAR and fCover CYCLOPES global products derived from VEGETATION: Part 1: Principles of the algorithm," Remote Sens. Environ, vol. 110, no. 3, 275-286. doi.org/10.1016/j.rse.2007.02.018

2. Berger J.D., Ludwig C., 2014. Contrasting adaptive strategies to terminal drought-stress gradients in Mediterranean legumes: phenology, productivity, and water relations in wild and domesticated Lupinus luteus L. J. Exp. Bot., 65, 6219-6229.

3. Bsaibes, A., Courault, D., Baret, F., Weiss, M., Olioso, A., Jacob, F., Hagolle, O., Marloi, O., Bertrand, N., Desfond, V., Kzemipour, F., 2009. Albedo and LAI estimates from FORMOSAT-2 data for crop monitoring. Remote Sens. Environ. vol. 113, no. 4, 716-729. doi.org/10.1016/j.rse.2008.11.014

4. Boissard, P., Pointel, J.G., Tranchefort, J., 1992. Estimation of the ground cover ratio of a wheat canopy using radiometry, Int. J. Remote Sens. 13(9), 1681-1692. 
5. Chang, L., Peng-Sen, S., Shi-Rong, L., 2016. A review of plant spectral reflectance response to water physiological changes. Chinese Journal of Plant Ecology, vol. 40 (1), 80-91.

6. Cho, M.A., Skidmore, A.K., 2006. A new technique for extracting the red edge position from hyperspectral data: The linear extrapolation method. Remote Sens. Environ, 101, 181-193.

7. Ecarnot, M., Compan, F., Roumet, F.P., 2013. Assessing leaf nitrogen content and leaf mass per unit area of wheat in the field throughout plant cycle with a portable spectrometer. Field Crop. Res. 140, 44-50.

8. Filella, I, Penuelas, J., 1994. The red edge position and shape as indicators of plant chlorophyll content, biomass and hydric status. Int. J. of Remote Sensing, 15(7): 1459-1470.

9. Fitzgerald, G.J., Rodriguez, D., O’Leary, G., 2010. Measuring and predicting canopy nitrogen nutrition in wheat using a spectral index-the canopy chlorophyll content index (CCCI). Field Crop. Res. 116, 318-324.

10. Gitelson, A.A., Kaufman, Y.J., Starkc, R., Rundquist. D., 2002. Novel algorithms for remote estimation of vegetation fraction. Remote Sens. Environ, 80, 76-87.

11. Goetz, S.J., 1997. Multi-sensor analysis of NDVI, surface temperature and biophysical variables at a mixed grassland site. Int. J. Remote Sens., 18, 71-94.

12. Glenn E.P., Huete, A.R., Nagler, P.L., Nelson S.G., 2008. Relationship between remotely sensed vegetation indices, canopy attributes and plant physiological processes: What vegetation indices can and cannot tell us about the landscape. Sensors, 8, 2136-2160.

13. Hansen, P.M., Schjoerring, J.K., 2003. Reflectance measurement of canopy biomass and nitrogen status in wheat crops using normalized difference vegetation indices and partial least squares regression. Remote Sens. Environ, 86, 542-553.

14.He, Y.H., Guo, X.L., and Wilmshurst, J., 2006. Studying mixed grassland ecosystems: suitable hyperspectral vegetation indices. Canadian J. Remote Sens., 32, 98-107.

15. Hinzman, L.D., Bauer, M.E., Daughtry, C.S.T., 1986. Effects of nitrogen fertilization on growth and reflectance characteristics of winter wheat, Remote Sens. Environ, 19, 47-61.

16. Huete, A., Didan, K., Miura, T., Rodriguez, E.P., Gao, X., Ferreira, L.G., 2002. Overview of the radiometric and biophysical performance of the MODIS vegetation indices. Remote Sens. Environ, 83, 195-213.

17. Kokhan S.S., 2011. Application of vegetation indexes derived from satellite images IRS-1D LISSIII for determination of crop status (In Ukrainian). Space Sci. \& Technol., 17(5):58-63.

18. Mulla D.J., 2013. Twenty-five years of remote sensing in precision agriculture: key advances and remaining knowledge gaps. Biosystems Engineering, vol. 114(4), 358-371
19. Myneni R.B., Maggion S., Iaquinta J., Privette J.L., Gobron N., Pinty B., Kimes D.S., Verstraete M.M., William D.L., 1995. Optical remote sensing of vegetation: Modeling, caveates, and algorithms. Remote Sens. Environ, 51, 169-188. Doi: 10.1016/0034-4257(94)00073-V

20. Niu, Z., Chen, Y., Sui, Z., Zhang, Q.Y., Zhao, C.J., 2000. Mechanism Analysis of Leaf Biochemical Concentration by High Spectral Remote Sensing. J. Remote Sens. 4, 125-130.

21. Post Launch Commissioning and Testing of Pleiades 1, 2012. ASTRIUM GEO-Information

22. Rahman, A.F., Gamon, J.A., Sims, D.A., Schmidts, M., 2003. Optimum pixel size for hyperspectral studies of ecosystem function in southern California chaparral and grassland. Remote Sens. Environ, 84, 192-207.

23. Schlerf, M., Alzberger, C., Hill, J., 2005. Remote sensing of forest biophysical variables using HyMap imaging spectrometer data. Remote Sens. Environ. 95 (2005), 177-194.

24. Tian, Y.C., Yao X., Yang, J., Cao, W.X., Hannaway D.B., Zhu, Y., 2011. Assessing newly developed and published vegetation indices for estimating rice leaf nitrogen concentration with ground-and spacebased hyperspectral reflectance. Fuel Energy Abstr. 120, 299-310.

25. Tucker, C.J., Holben, B.N., Elgin J.H., McMurtrey G.J. III, 1981. Remote sensing of total dry-matter accumulation in winter wheat, Remote Sens. Environ, 11, 171-189.

26. Turner, D.P., Cohen, W.D., Kennedy, R.E., Fassnacht, K.S., Briggs, J.M., 1999. Relationships between Leaf Area Index and Landsat TM Spectral Vegetation Indices across Three Temperate Zone Sites. Remote Sens. Environ, 70, 52-68.

27. Verrelst J., Romijn E., Kooistra L., 2012. Mapping vegetation density in a heterogeneous river fl31-oodplain ecosystem using pointable CHRIS/ PROBA data. Remote Sens. 4, 2866-2889.

28. Viña1 A., Gitelson, A.A., 2005. Geophysical Research Letters, vol. 32, L17403.

29. Wuest, S.B., Cassman, K.J., 1992. Fertilizer-nitrogen use efficiency of irrigated wheat: I. uptake efficiency of preplant versus late-season application. J. Argon, 84, 682-688.

30. Xue, J., Su, B., 2017. Significant Remote Sensing Vegetation Indices: A Review of Developments and Applications. Journal of Sensors Volume 2017, Article ID 1353691, 17 pages.

31. Zhang, C., Kovacs. J.M., 2012. The application of smallunmanned aerial systems for precision agriculture: a review. Precision Agriculture, vol. 13 (6), 693-712.

32. Zheng, D., Rademacher, J., Chen, J., Crow, T., Bresee, M., Le Moine, J., Ryu, S., 2004. Estimating aboveground biomass using Landsat $7 \mathrm{ETM}+$ data across a managed landscape in northern Wisconsin, USA. Remote Sens. Environ, 93(3), 402-411. 